University of Zurich

Department of Economics

Working Paper Series

ISSN 1664-7041 (print)

ISSN 1664-705X (online)

Working Paper No. 155

\title{
Elastic contests and the robustness of the all-pay auction
}

Christian Ewerhart

May 2014 


\title{
Elastic contests and the robustness of the all-pay auction*
}

\author{
Christian Ewerhart**
}

First version: February 15, 2012

Revised version: May 5, 2014

*) An earlier version has been circulated under the title "Log-supermodular contests and the robustness of the all-pay auction." For useful discussions, I would like to thank Ayre Hillman, Kai Konrad, Dan Kovenock, Wolfgang Leininger, David Malueg, Benny Moldovanu, David Peréz-Castrillo, Larry Samuelson, Aner Sela, Ron Siegel, and Paul Schweinzer. The paper has also benefitted from comments received from participants of the Annual Conference of the Association for Public Economic Theory in Taipei, the North American Summer Meeting at Northwestern University, and the SAET conference in Paris.

**) Department of Economics, University of Zurich, Schönberggasse 1, 8001 Zurich, Switzerland; e-mail: christian.ewerhart@econ.uzh.ch; phone: +4144-6343733. 


\title{
Elastic contests and the robustness of the all-pay auction
}

\begin{abstract}
This paper studies a large class of imperfectly discriminating contests, referred to as elastic contests, that induce players to either overbid a standing bid or to abstain from bidding altogether. Many common forms of contest are elastic. In any equilibrium of an elastic contest, there is complete rent dissipation for all but at most one player. This result is used to show that in any sufficiently decisive anonymous standard contest, any equilibrium is an all-pay auction equilibrium. Thus, the analysis offers strong support for the robustness of the all-pay auction. The approach also delivers definite answers regarding the extent of rent dissipation in Tullock contests with intermediate values of the decisiveness parameter.
\end{abstract}

Keywords. Contests, all-pay auction; rent-seeking, mixed Nash equilibrium, rent dissipation.

JEL-Codes. C72 - Noncooperative Games; D45 - Rationing; Licensing; D72 - Political Processes: Rent-Seeking, Lobbying, Elections, Legislatures, and Voting Behavior; L12 - Monopoly; Monopolization Strategies. 


\section{Introduction}

One of the principal concerns of contest theory has been the determination of "wasteful" rent dissipation in general situations of rivalry. ${ }^{1}$ Such rivalry has often been modeled in terms of the (first-price) all-pay auction, in which the highest bid wins with certainty. ${ }^{2}$ Using the all-pay auction and its variants is convenient in particular because the corresponding equilibrium is wellunderstood through contributions by Hillman and Samet (1987), Hillman and Riley (1989), Baye et al. (1996), and Siegel (2009, 2010). However, assuming an entirely deterministic relationship between bids and allocation is restrictive in some applications. For example, in a sporting contest, not only the quality of the field and contributed effort, but also the uncertainty of outcome matters (Szymanski, 2003). It is, therefore, desirable to characterize the equilibrium also in contests that are not perfectly discriminating. Complete results in this area, however, have been difficult to obtain. ${ }^{3}$

\footnotetext{
${ }^{1}$ For example, in a patent race (cf. Loury, 1979; Dasgupta and Stiglitz, 1980), sunk and irreversible research investments determine which firm is more likely to be the first in the market. For an introduction to contest theory, see Konrad (2007).

${ }^{2}$ See, e.g., applications to areas such as sales promotion (Varian, 1980; Narasimhan, 1988), interbank competition (Broecker, 1990), monopoly (Ellingsen, 1991), market microstructure (Dennert, 1993), political lobbying (Baye et al. 1993; Che and Gale, 1998), and contests for status (Moldovanu et al., 2007).

${ }^{3}$ For illustration, consider Tullock's (1980) rent-seeking game. Two players $i$ and $j$ produce lottery tickets for a prize of value $v>0$. For respective investment levels $x_{i} \geq 0$ and $x_{j} \geq 0$, player $i$ 's payoff is given by

$$
\Pi_{i}\left(x_{i}, x_{j}\right)=p_{i}\left(x_{i}, x_{j}\right) v-x_{i},
$$

where

$$
p_{i}\left(x_{i}, x_{j}\right)=\left\{\begin{array}{cc}
\frac{x_{i}^{R}}{x_{i}^{R}+x_{j}^{R}} & \text { if } x_{i}^{R}+x_{j}^{R}>0 \\
\frac{1}{2} & \text { if } x_{i}^{R}+x_{j}^{R}=0
\end{array}\right.
$$

denotes player $i$ 's probability of winning, and $R>0$ is the decisiveness parameter. For values of $R \leq 2$, the equilibrium can be found by an analysis of the players' first-order conditions (see, e.g., Pérez-Castrillo and Verdier, 1992). On the other hand, in the limit case $R=\infty$, the game corresponds to the all-pay auction. For intermediate values of $R$, i.e., for $2<R<\infty$, the rent-seeking game has proven to be much less tractable.
} 
Three notable contributions have made progress on this issue. Baye et al. (1994) have pointed out that, in the symmetric two-player Tullock contest with intermediate values of the decisiveness parameter, a mixed equilibrium with complete rent dissipation can be found as the limit of equilibria in finite games. Extending these results, Alcade and Dahm (2010) have identified a wide class of contests that allow an all-pay auction equilibrium, i.e., an equilibrium in which players' respective probabilities of participation, expected bids, ex-ante winning probabilities, and expected payoffs are all the same as in the equilibrium of the corresponding all-pay auction. Using a different approach, Che and Gale (2000) have characterized equilibria for differenceform contests with a uniform distribution of the noise term. These equilibria capture a preemption effect, in the sense that an increased asymmetry in valuations weakly reduces the extent of rent dissipation. Overall, however, less seems to be known about the possibility of equilibria with other properties. ${ }^{4}$

The present paper proposes a new approach to characterizing the equilibrium set of a large class of imperfectly discriminating contests. The approach exploits the fact that in many commonly used specifications of contests, there is a simple relationship between marginal and total payoffs for low-bidding players. Since players in contests can always ensure themselves a nonnegative payoff by remaining purely passive, this relationship allows to formulate conditions, collected in the definition of an elastic contest, under which a bidder either strictly overbids any standing bid or abstains from bidding altogether.

\footnotetext{
${ }^{4}$ This point may be important, though. For example, alternative equilibria promising higher rents for some or all of the players might be more likely to be coordinated upon. Also, knowing the entire equilibrium set is relevant for the comparative statics of the model.
} 
Then, given the strong incentive to overbid, any given positive bid can be rationalized only if the equilibrium belief assigns some probability weight to strictly smaller bids. As a consequence, any equilibrium in an elastic contest involves either arbitrarily small positive bids or non-participation, which has strong implications for players' equilibrium rents.

The following results are obtained. First, it is shown that generally in elastic contests, all rents are competed away in any equilibrium for all but at most one player. In particular, in a symmetric elastic contest, all rents are entirely dissipated in any symmetric equilibrium. Further, there is at most one active player in any pure-strategy equilibrium of an elastic contest. Quite specific results can be obtained when the elastic contest is standard and anonymous. ${ }^{5}$ Between two players, any equilibrium in such a contest is an all-pay auction equilibrium. This result extends to the case of three or more players when the contest is, in addition, sufficiently decisive. Together, these findings shed light on the robustness of the equilibrium prediction obtained for the all-pay auction. The analysis also yields some definite answers regarding the extent of rent dissipation in the popular Tullock contest.

The rest of the paper is structured as follows. Section 2 outlines the setup. Section 3 illustrates the approach of the paper using the Tullock game. The formal notion of an elastic contest is introduced in Section 4. Examples are given in Section 5. Section 6 contains the equilibrium analysis in the general case. The robustness of the all-pay auction is discussed in Section 7 . Section 8 concludes. All proofs are in the Appendix.

\footnotetext{
${ }^{5}$ In a standard contest, payoffs are additively separable, players' valuations are constant, and costs are linear. In an anonymous contest, winning probabilities depend only on efforts, and not on the players' names. See Section 7.
} 


\section{Set-up}

This section introduces the class of games with continuous strategies and normalized payoffs, which serves as the basic framework for the subsequent analysis. Assumptions made in this section will be used tacitly throughout the paper.

There are $N \geq 2$ players. Each player $i=1, \ldots, N$ chooses a bid $x_{i} \geq 0$. Bids will alternatively be referred to as either effort levels or investments. Decisions are made simultaneously and independently. Player $i$ 's payoff is denoted by $\Pi_{i}\left(x_{i}, x_{-i}\right)$, where $x_{-i}=\left(x_{1}, \ldots, x_{i-1}, x_{i+1}, \ldots, x_{N}\right){ }^{6}$ For notational convenience, payoffs are assumed to be normalized, i.e., $\Pi_{i}\left(0, x_{-i}\right)=0$ for any $x_{-i} \neq 0$. Many commonly used classes of contests possess normalized payoffs (cf. Section 5). In general, any given payoff function $\widehat{\Pi}_{i}\left(x_{i}, x_{-i}\right)$ can be normalized by redefining payoffs as $\Pi_{i}\left(x_{i}, x_{-i}\right)=\widehat{\Pi}_{i}\left(x_{i}, x_{-i}\right)-\widehat{\Pi}_{i}\left(0, x_{-i}\right)$. Thus, normalized payoffs can be assumed without loss of generality. For technical convenience, it is assumed that there exists, for any $i=1, \ldots, N$, some bid level $x_{i}^{\max }>0$ such that $\Pi_{i}\left(x_{i}, x_{-i}\right)<0$ for any $x_{i}>x_{i}^{\max }$ and for any $x_{-i} \in X_{-i} \cdot{ }^{7}$ It will also be assumed that $\Pi_{i}\left(x_{i}, x_{-i}\right)$ is bounded from above, and continuously differentiable at any $\left(x_{i}, x_{-i}\right) \neq 0$, for any $i=1, \ldots, N$.

The definition of a Nash equilibrium in mixed strategies follows Dasgupta and Maskin (1986). Since, by assumption, the effective choice set of player $i$ corresponds to the bounded interval $X_{i}=\left[0, x_{i}^{\max }\right]$, a mixed strategy for player $i$ may be defined as a probability distribution $\mu_{i}$ on the Borel sets of $X_{i}$. Let $D\left(X_{i}\right)$ denote the set of mixed strategies for player $i$. Then a mixed

\footnotetext{
${ }^{6}$ Also the notation $x_{-i, j}=\left(x_{1}, \ldots, x_{i-1}, x_{i+1}, \ldots, x_{j-1}, x_{j+1}, \ldots, x_{N}\right)$ will be used. For example, $\Pi_{i}\left(x_{i}, x_{-i}\right)=\Pi_{i}\left(x_{i}, x_{j}, x_{-i, j}\right)$, etc.

${ }^{7}$ E.g., in the earlier example, it would suffice to choose $x_{i}^{\max }=v$.
} 
equilibrium is a tuple $\left(\mu_{1}^{*}, \ldots, \mu_{N}^{*}\right)$, representing a probability distribution $\mu_{i}^{*} \in$ $D\left(X_{i}\right)$ for each player $i=1, \ldots, N$, such that ex-ante expected payoffs are maximized by each player $i$, i.e., such that

$$
\begin{aligned}
\Pi_{i}^{*} & \equiv \int \Pi_{i}\left(x_{i}, x_{-i}\right) d\left(\mu_{i}^{*}\left(x_{i}\right) \times \mu_{-i}^{*}\left(x_{-i}\right)\right) \\
& =\max _{\mu_{i} \in D\left(X_{i}\right)} \int \Pi_{i}\left(x_{i}, x_{-i}\right) d\left(\mu_{i}\left(x_{i}\right) \times \mu_{-i}^{*}\left(x_{-i}\right)\right),
\end{aligned}
$$

where $\mu_{-i}^{*}\left(x_{-i}\right)=\prod_{j \neq i} \mu_{j}^{*}\left(x_{j}\right)$. A mixed equilibrium $\left(\mu_{1}^{*}, \ldots, \mu_{N}^{*}\right)$ is called symmetric if $\mu_{1}^{*}=\ldots=\mu_{N}^{*}$. Since payoffs are normalized, player $i$ 's expected equilibrium payoff $\Pi_{i}^{*}$ will be referred to also as player $i$ 's equilibrium rent. ${ }^{8}$

For a mixed strategy $\mu_{i} \in D\left(X_{i}\right)$, let $S\left(\mu_{i}\right)$ denote the support set of $\mu_{i}$. Since $X_{i}$ is a bounded and closed subset of $\mathbb{R}_{+}$, so is $S\left(\mu_{i}\right)$. Write $\underline{x}_{i}=\min S\left(\mu_{i}\right)$ for player $i$ 's lowest bid, and $\bar{x}_{i}=\max S\left(\mu_{i}\right)$ for player $i$ 's highest bid. Player $i$ is said to use arbitrarily small bids if $\underline{x}_{i}=0$. By definition, $\mu_{i}(\{0\})$ is player $i$ 's probability of bidding zero, i.e., player $i$ 's probability of non-participation. Player $i$ will be called purely passive if $\mu_{i}(\{0\})=1$, active if $\mu_{i}(\{0\})<1$, and always active if $\mu_{i}(\{0\})=0$. If player $i$ is active, then $\underline{x}_{i}^{+}=\inf S\left(\mu_{i}\right) \backslash\{0\}$ denotes the infimum of all positive bids used by player $i$. Player $i$ uses arbitrarily small positive bids if $\underline{x}_{i}^{+}=0$.

\section{Introductory example}

To illustrate the approach of the paper, it will be shown now in an essentially self-contained way that all rents are dissipated in any symmetric equilibrium

\footnotetext{
${ }^{8}$ The mixed equilibrium exists under fairly weak conditions. Indeed, by Theorem 5 in Dasgupta and Maskin (1986), it suffices to ensure that $\Pi_{i}\left(x_{i}, 0\right)$ is lower semi-continuous at $x_{i}=0$, for any $i=1, \ldots, N$, and that $\sum_{i=1}^{N} \Pi_{i}\left(x_{1}, \ldots, x_{N}\right)$ is upper semi-continuous at the origin. These conditions often hold in specific examples of contests. See Baye et al. (1994), Yang (1994), and Alcade and Dahm (2010).
} 
of the two-player Tullock game with finite $R>2 .{ }^{9}$ Even for this simple example, little has been known before about the equilibrium set except that (i) it does not contain any pure-strategy equilibrium, and (ii) it contains a mixed equilibrium with complete rent dissipation. Indeed, Konrad and Kovenock (2009, p. 258) still called the characterization of the equilibrium for $2<R<\infty$ an "open problem."

Figure 1 depicts player 1's payoffs as a function of his own bid $x_{1}$ for various realizations of player 2's bid $x_{2} \cdot{ }^{10}$ The dashed line corresponds to player 1's payoffs when the bids of the two players are of equal size. One can

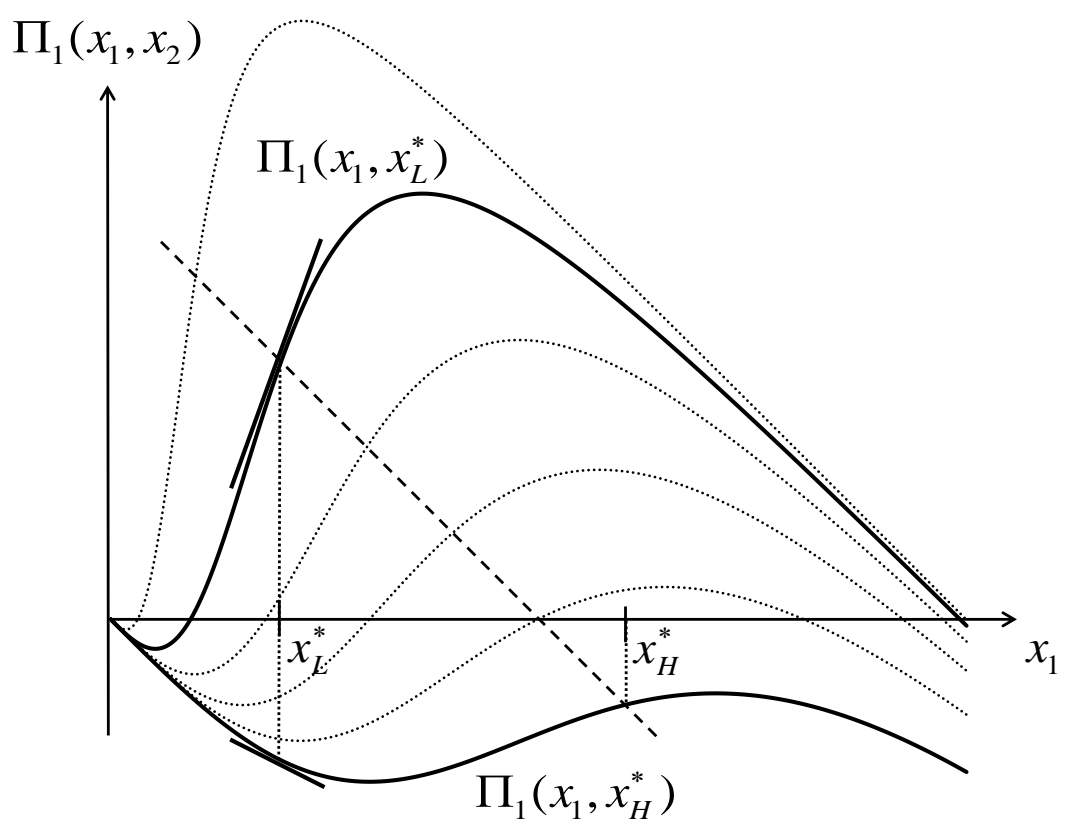

Fig. 1: Player 1's payoffs as a function of $x_{1}$, for various realizations of $x_{2}$

\footnotetext{
${ }^{9}$ The restriction to symmetric equilibria is made here solely for expositional reasons. It will be shown later in the paper that rent dissipation is complete also in any asymmetric equilibrium.

${ }^{10}$ The realizations of player 2 's bid are $x_{2} \in\left\{0.1,0.2=x_{L}^{*}, 0.3,0.4,0.5,0.6=x_{H}^{*}\right\}$. Further, $v=1$ and $R=3$.
} 
see that player 1's payoffs are strictly upward-sloping in $x_{1}$ at the respective intersection points with the dashed line. Thus, a player will either overbid the competing bid or abstain from bidding altogether.

Consider first a candidate equilibrium in mixed strategies with two bid realizations $x_{H}^{*}>x_{L}^{*}>0$, used with respective probabilities $q_{H}^{*}>0$ and $q_{L}^{*}=1-q_{H}^{*}>0$. Focus on the lower bid $x_{L}^{*}$. In equilibrium, choosing $x_{L}^{*}$ must generate a nonnegative expected payoff for player 1, i.e.,

$$
q_{L}^{*} \Pi_{1}\left(x_{L}^{*}, x_{L}^{*}\right)+q_{H}^{*} \Pi_{1}\left(x_{L}^{*}, x_{H}^{*}\right) \geq 0 .
$$

Moreover, the first-order condition for an interior optimum must hold at $x_{L}^{*}$, i.e.,

$$
q_{L}^{*} \frac{\partial \Pi_{1}\left(x_{L}^{*}, x_{L}^{*}\right)}{\partial x_{1}}+q_{H}^{*} \frac{\partial \Pi_{1}\left(x_{L}^{*}, x_{H}^{*}\right)}{\partial x_{1}}=0
$$

The crucial point to note is that conditions (5) and (6) are inconsistent. Intuitively, in Figure 1, player 1's positive marginal payoff when $x_{2}=x_{L}^{*}$ is much larger in absolute terms than the negative marginal payoff when $x_{2}=x_{H}^{*}$. Therefore, choosing $q_{L}^{*}=1-q_{H}^{*}$ so as to satisfy condition (6) requires $q_{L}^{*}$ to be quite small, which leads to negative expected payoffs for player 1 , so that (5) fails to hold. ${ }^{11}$ Thus, there is no symmetric equilibrium with only two bid levels.

${ }^{11}$ Formally, a careful calculation shows that for $R>2$,

$$
\frac{\partial \Pi_{1}\left(x_{L}^{*}, x_{L}^{*}\right)}{\partial x_{1}}=\frac{R v}{4 x_{L}^{*}}-1>\frac{1}{x_{L}^{*}}\left(\frac{v}{2}-x_{L}^{*}\right)=\frac{1}{x_{L}^{*}} \Pi_{1}\left(x_{L}^{*}, x_{L}^{*}\right),
$$

and similarly,

$$
\frac{\partial \Pi_{1}\left(x_{L}^{*}, x_{H}^{*}\right)}{\partial x_{1}}=\frac{R\left(x_{L}^{*}\right)^{R-1}\left(x_{H}^{*}\right)^{R}}{\left(\left(x_{H}^{*}\right)^{R}+\left(x_{L}^{*}\right)^{R}\right)^{2}} v-1>\frac{1}{x_{L}^{*}} \Pi_{1}\left(x_{L}^{*}, x_{H}^{*}\right) .
$$

Taking a weighted average of inequalities (7) and (8), with respective weights $q_{L}^{*}$ and $q_{H}^{*}$, shows that conditions (5) and (6) are indeed inconsistent. 
The argument given above extends in a straightforward way to candidate equilibria with more general bid distributions. Regardless of the form of the distribution, assuming a lowest positive bid, i.e., $\underline{x}_{1}=\underline{x}_{2}>0$, leads to a contradiction. Therefore, $\underline{x}_{1}=\underline{x}_{2}=0$, and any symmetric equilibrium involves arbitrary small bids. Arbitrarily small bids, however, translate into arbitrarily low winning probabilities and hence, into arbitrarily small expected payoffs. Thus, all rents are dissipated.

\section{Formal definition}

This section introduces the notion of an elastic contest. The definition is given first in the symmetric case.

Definition 4.1. A symmetric $N$-player game with normalized payoffs is a symmetric elastic contest if for any $x_{i}^{0}>0$, there is some constant $\lambda=\lambda\left(x_{i}^{0}\right)>0$ such that

$$
\frac{\partial \Pi_{i}\left(x_{i}^{0}, x_{-i}\right)}{\partial x_{i}}>\lambda \Pi_{i}\left(x_{i}^{0}, x_{-i}\right)
$$

holds for any $x_{-i} \in X_{-i}$ satisfying $x_{j} \geq x_{i}^{0}$ for all $j \neq i$.

The definition requires that, if some given bid of player $i$ is weakly matched by all competitors, then player $i$ 's marginal payoff strictly exceeds some multiple of player $i$ 's total payoff. For an assumed lowest equilibrium bid $x_{i}^{0}=\underline{x}_{i}>0$, integrating condition (9) over all possible vectors of competing bids $x_{-i}$ and taking account of the participation constraint implies that there will be a strict incentive for player $i$ to increase her bid. Thus, Definition 4.1 implies that overbidding or non-participation are the only form of optimal response in a symmetric equilibrium, which is what is needed in the sequel. 
Here is a generalization of Definition 4.1 to asymmetric settings.

Definition 4.2. An N-player game with normalized payoffs is an elastic contest if for any two players $i, j \in\{1, \ldots, N\}$ with $i \neq j$, the following two conditions are satisfied:

(L1) For any $x_{i}^{0}>0$ and $x_{j}^{0}>0$ there is, possibly after exchanging $i$ and $j$, some constant $\lambda=\lambda\left(x_{i}^{0}, x_{j}^{0}\right)>0$ such that

$$
\frac{\partial \Pi_{i}\left(x_{i}^{0}, x_{j}, x_{-i, j}\right)}{\partial x_{i}}>\lambda \Pi_{i}\left(x_{i}^{0}, x_{j}, x_{-i, j}\right)
$$

holds for any $x_{j} \geq x_{j}^{0}$ and for any $x_{-i, j} \in X_{-i, j}$.

(L2) In condition (L1), the exchange of $i$ and $j$ is not necessary if $x_{i}^{0}>0$ is sufficiently small given $x_{j}^{0}>0$.

The somewhat more involved conditions of Definition 4.2 are owned to the fact that when the contest is asymmetric, then the unraveling of the equilibrium does not necessarily evolve on a common scale across players as before.

\section{Examples of elastic contests}

This section illustrates the scope of Definitions 4.1 and 4.2 using a number of examples.

\subsection{Logit contests}

The logit contest has been studied, in particular, by Dixit (1987), Skaperdas (1996), and Cornes and Hartley (2005). Fix valuations $v_{1} \geq \ldots \geq v_{N}>0$, and let player $i$ 's payoff be given by

$$
\Pi_{i}\left(x_{i}, x_{-i}\right)=p_{i}\left(x_{i}, x_{-i}\right) v_{i}-x_{i} .
$$


where

$$
p_{i}\left(x_{i}, x_{-i}\right)=\frac{h_{i}\left(x_{i}\right)}{h_{i}\left(x_{i}\right)+\sum_{j \neq i} h_{j}\left(x_{j}\right)},
$$

if the denominator in (12) is positive, and by $p_{i}\left(x_{i}, x_{-i}\right)=\frac{1}{N}$, otherwise. Here, $h_{i}($.$) is any continuously differentiable impact function with h_{i}(0)=0$ and $h_{i}^{\prime}\left(x_{i}\right)>0$ for $x_{i}>0$.

The logit contest is elastic provided that $x_{i} h_{i}^{\prime}\left(x_{i}\right) / h_{i}\left(x_{i}\right)>2$ for any $x_{i} \in\left[0, x_{i}^{\max }\right]$ and for all $i=1, \ldots, N$. This follows directly from Theorem 5.2 below. For example, an asymmetric $N$-player rent-seeking game with impact functions $h_{i}\left(x_{i}\right)=a_{i} x_{i}^{R_{i}}$, for arbitrary parameters $a_{i}>0$, is elastic if $R_{i}>2$ for all $i=1, \ldots, N$.

\subsection{Difference-form contests}

The difference-form specification is plausible when the probability to win depends on the difference in investments as, e.g., in warfare. This form of contest has been studied, in particular, by Hirshleifer (1989) and Baik (1998). I will focus on the two-player case. Payoffs to player $i=1,2$ are given by

$$
\widehat{\Pi}_{i}\left(x_{i}, x_{j}\right)=F_{i}\left(x_{i}-x_{j}\right) v_{i}-x_{i},
$$

where $F_{i}(z)=1-F_{j}(-z)$ is the distribution function of the noise term for player $i$, assumed to be twice continuously differentiable, and $v_{1} \geq v_{2}>0$. In contrast to the logit specification, a zero bid may win against a positive bid in a difference-form contest. It is therefore convenient to work with normalized payoffs

$$
\Pi_{i}\left(x_{i}, x_{j}\right)=\left(F_{i}\left(x_{i}-x_{j}\right)-F_{i}\left(-x_{j}\right)\right) v_{i}-x_{i} .
$$

The next result gives a simple sufficient condition for a difference-form specification to define an elastic contest. 
Theorem 5.1. Assume that the density of the noise distribution, $f_{i}(z)=$ $f_{j}(-z)$, is hump-shaped with mode zero. ${ }^{12}$ Then, the normalized specification (14) defines an elastic contest.

For illustration, consider the logistic specification proposed by Hirshleifer (1989), where player $i$ 's payoffs are given by

$$
\widehat{\Pi}_{i}\left(x_{i}, x_{j}\right)=\frac{\exp \left(\beta x_{i}\right)}{\exp \left(\beta x_{i}\right)+\exp \left(\beta x_{j}\right)} v_{i}-x_{i}
$$

with $\beta>0$. This is obviously a special case of $(13)$ with $F_{i}(z)=F_{j}(z)=$ $\frac{1}{1+\exp (-\beta z)}$. The corresponding density function is easily seen to be humpshaped with mode zero. Thus, the payoff-normalized logistic contest is elastic, regardless of the parameter. ${ }^{13}$

\subsection{Contests with additively separable payoffs}

In a more general class of examples, player $i$ 's payoff is given by

$$
\Pi_{i}\left(x_{i}, x_{-i}\right)=p_{i}\left(x_{i}, x_{-i}\right) V_{i}\left(x_{i}, x_{-i}\right)-C_{i}\left(x_{i}, x_{-i}\right)
$$

where $p_{i}($.$) is a contest success function, V_{i}($.$) is the value of the prize to$ bidder $i$, which may depend on the vector of bids, and $C_{i}($.$) is player i$ 's cost function, allowing likewise for externalities. Contests with additively separable payoffs encompass many cases of interest. E.g., Baye and Hoppe (2003) consider specification (16) with linear costs. Also the cases of nonlinear costs (González-Díaz, 2010) and conditional investments (Siegel, 2009;

\footnotetext{
${ }^{12}$ I.e., $f_{i}(z)$ is strictly increasing when $z \leq 0$, and strictly declining when $z \geq 0$.

${ }^{13}$ If, as in Che and Gale (2000), the noise term is distributed uniformly on an interval $\left[-\frac{1}{2 s},+\frac{1}{2 s}\right]$, where $s>0$ is a constant, then the game can be approximated by elastic contests satisfying the conditions of Theorem 5.1 .
} 
2010) are covered. ${ }^{14}$

Regarding contest success functions, it will be assumed that $p_{i}() \geq$.0 , that $\sum_{i=1}^{N} p_{i}\left(x_{1}, \ldots, x_{N}\right)=1$, and that $p_{i}($.$) is twice continuously differentiable$ at any $\left(x_{i}, x_{-i}\right) \neq 0$. It will also be assumed that $p_{i}($.$) is monotone, i.e., that$ $p_{i}\left(x_{i}, x_{j}, x_{-i, j}\right)$ is weakly declining in $x_{j}$, for any $i \neq j$, and that a zero bid never wins against a positive bid, i.e., that $p_{i}\left(x_{i}, x_{-i}\right)>0$ for $x_{-i} \neq 0$ implies $x_{i}>0$. Finally, assume $p_{i}\left(x_{i}, x_{-i}\right)>0$ for any $x_{i}>0$. The functions $V_{i}($. and $C_{i}($.$) are assumed to be twice differentiable. Moreover, V_{i}\left(x_{i}, x_{-i}\right)>0$ and $C_{i}\left(x_{i}, x_{-i}\right)>0$ if $x_{i}>0$.

There is a simple way to check that a given additively separable contest is elastic. Define the decisiveness of $p_{i}($.$) at a bid vector \left(x_{i}, x_{-i}\right)$ with $x_{i}>0$ and $x_{-i} \neq 0$ by

$$
\rho_{i}\left(x_{i}, x_{-i}\right)=\frac{x_{i} \partial p_{i}\left(x_{i}, x_{-i}\right) / \partial x_{i}}{p_{i}\left(x_{i}, x_{-i}\right)\left(1-p_{i}\left(x_{i}, x_{-i}\right)\right)} .
$$

Note that $\rho_{i}$ is just the elasticity of $p_{i}() /.\left(1-p_{i}().\right)$ with respect to $x_{i}$. For example, in the asymmetric Tullock contest, $\rho_{i}(.) \equiv R_{i} \cdot{ }^{15}$ More generally, in the logit contest, $\rho_{i}($.$) corresponds to the elasticity of player i$ 's impact function. Thus, the decisiveness is a natural extension of existing concepts. Let $\underline{\rho}$ denote the joint infimum of the functions $\rho_{i}($.$) . Further, denote by$

$$
\gamma_{i}\left(x_{i}, x_{-i}\right)=\frac{x_{i} \partial C_{i}\left(x_{i}, x_{-i}\right) / \partial x_{i}}{C_{i}\left(x_{i}, x_{-i}\right)}
$$

\footnotetext{
${ }^{14}$ In an imperfectly discriminating contest with conditional investments, player $i$ 's payoffs are given by

$$
\Pi_{i}\left(x_{i}, x_{-i}\right)=p_{i}\left(x_{i}, x_{-i}\right) V_{i}^{\#}\left(x_{i}\right)-\left(1-p_{i}\left(x_{i}, x_{-i}\right)\right) C_{i}^{\#}\left(x_{i}\right),
$$

where $V_{i}^{\#}\left(x_{i}\right)$ is player $i$ 's valuation of winning, and $C_{i}^{\#}\left(x_{i}\right)$ is player $i$ 's valuation of losing. By defining $V_{i}\left(x_{i}, x_{-i}\right)=V_{i}^{\#}\left(x_{i}\right)+C_{i}^{\#}\left(x_{i}\right)$ and $C_{i}\left(x_{i}, x_{-i}\right)=C_{i}^{\#}\left(x_{i}\right)$, specification (17) clearly becomes a special case of (16).

${ }^{15}$ The fact that Tullock's $R$ may be interpreted as an elasticity of the odds of winning was noted before. See Wang (2010).
} 
the own-bid elasticity of player $i$ 's cost function for $x_{i}>0$, with joint supremum $\bar{\gamma}$. Finally, denote by

$$
\alpha_{i}\left(x_{i}, x_{-i}\right)=\frac{x_{i} \partial V_{i}\left(x_{i}, x_{-i}\right) / \partial x_{i}}{V_{i}\left(x_{i}, x_{-i}\right)}
$$

the own-bid elasticity of player $i$ 's valuation for $x_{i}>0$, and by $\underline{\alpha}$ the joint infimum of the functions $\alpha_{i}($.$) .$

The following result offers sufficient conditions for a contest of the form (16) to be elastic.

Theorem 5.2. A contest with additively separable payoffs is elastic if $\underline{\rho}>$ $2(\bar{\gamma}-\underline{\alpha})$. Moreover, a symmetric contest with additively separable payoffs is a symmetric elastic contest if $\underline{\rho}>\frac{N}{N-1}(\bar{\gamma}-\underline{\alpha})$.

The joint condition on the decisiveness and on the elasticities of valuation and costs is intuitive. For example, the requirement on the decisiveness becomes more restrictive as the cost functions become more convex ( $\bar{\gamma}$ increases), or the scale economies of the valuation become weaker ( $\underline{\alpha}$ decreases). Thus, Theorem 5.2 further illustrates the flexibility of Definitions 4.1 and 4.2.

\subsection{Risk aversion}

Allowing for risk-aversion in imperfectly discriminating contests is certainly desirable. An overview over existing contributions can be found in Treich (2010).

Let $u_{i}($.$) denote player i$ 's utility function, assumed to be twice continuously differentiable, with $u_{i}^{\prime}()>$.0 and $u_{i}^{\prime \prime}() \leq$.0 . For a vector of bids $\left(x_{i}, x_{-i}\right)$, player $i$ 's expected utility is given by

$$
\Pi_{i}\left(x_{i}, x_{-i}\right)=p_{i}\left(x_{i}, x_{-i}\right) u_{i}\left(w_{i}+v_{i}-x_{i}\right)+\left(1-p_{i}\left(x_{i}, x_{-i}\right)\right) u_{i}\left(w_{i}-x_{i}\right),
$$


where $w_{i}$ denotes player $i$ 's initial wealth, and $p_{i}($.$) an arbitrary contest suc-$ cess function, assumed to satisfy the assumptions of the previous subsection. Note that payoffs are normalized in this specification provided that $u_{i}\left(w_{i}\right)=0$ for $i=1, \ldots, N$. For $z \in \mathbb{R}$, let

$$
\eta_{i}(z)=-\frac{u_{i}^{\prime \prime}(z)}{u_{i}^{\prime}(z)}
$$

denote player $i$ 's Arrow-Pratt coefficient of absolute risk aversion, and let $\bar{\eta}$ be the joint supremum of the functions $\eta_{i}(z)$.

The following result identifies a large class of elastic contests with risk aversion.

Theorem 5.3. The $N$-player contest of the form (21) is an elastic contest after normalization of payoffs if $\underline{\rho}>2 \exp \left(\bar{\eta} v_{1}\right)$.

Obviously, the case $\bar{\eta}=0$ just corresponds to the case of risk-neutrality. However, the restriction on the elasticity of the contest success function becomes tighter as the coefficient of absolute risk aversion increases.

\section{Equilibrium analysis}

This section offers a fairly complete characterization of equilibrium payoffs for elastic contests. The characterization is obtained by a sequence of two lemmata.

It is shown first that if some player is always active, then all other players necessarily use arbitrarily small bids.

Lemma 6.1. Consider an elastic $N$-player contest. In any mixed equilibrium $\left(\mu_{1}^{*}, \ldots, \mu_{N}^{*}\right)$, if some player $i \in\{1, \ldots, N\}$ is always active, then all other players use arbitrarily small bids, i.e., $\underline{x}_{j}=0$ for all $j \neq i$. 
The intuition here is simply that in an elastic contest, a strictly positive bid $x_{i}>0$ can be rationalized only by an equilibrium belief that assigns positive probability to bids that are less likely to win than $x_{i}>0$. But if $\underline{x}_{j}>0$ for some player $j \neq i$, then some bid that is less likely to win, either $x_{i}$ or $\underline{x}_{j}$, cannot be rationalized.

Lemma 6.2. Consider an elastic $N$-player contest. Then, in any equilibrium $\left(\mu_{1}^{*}, \ldots, \mu_{N}^{*}\right)$, if there is some player $i \in\{1, \ldots, N\}$ that is always active, then all other players have zero expected payoffs in equilibrium, i.e., $\Pi_{j}^{*}=0$ for all $j \neq i$.

While the proof of this lemma is somewhat technical, the intuition is straightforward. If some player $i$ is always active, then by an immediate application of Lemma 6.1 , necessarily $\underline{x}_{j}=0$ for any $j \neq i$. However, the optimality of arbitrarily small bids clearly prohibits any positive rents for players $j \neq i$, as a consequence of payoffs being continuous at non-zero bid vectors.

The main result of this section is the following.

Theorem 6.3. Consider an elastic $N$-player contest. Then, in any equilibrium $\left(\mu_{1}^{*}, \ldots, \mu_{N}^{*}\right)$, there exists some $i \in\{1, \ldots, N\}$ such that $\Pi_{j}^{*}=0$ for all $j \neq i$.

Thus, in any elastic contest, there is at most one player that earns a positive rent. All other rents are competed away in any equilibrium. This type of result appears in various forms in the literature on perfectly discriminating contests (see, e.g., Siegel, 2009), but has been less commonly associated with the theory of imperfectly discriminating contests. 
The section concludes with two corollaries of the analysis above. The first concerns symmetric equilibria.

Corollary 6.4. In any symmetric equilibrium of a symmetric elastic $N$ player contest, there is complete rent dissipation.

For example, in the symmetric Tullock contest with decisiveness parameter $R>\frac{N}{N-1}$, any symmetric equilibrium entails complete rent dissipation. ${ }^{16}$

The second corollary concerns pure-strategy equilibria. Here, a pure strategy is simply a strategy whose support set is a singleton. If bidders are restricted to pure strategies, then the use of arbitrarily small positive bids is not feasible. As a consequence, at most one bidder may be active.

Corollary 6.5. In any pure-strategy equilibrium of an elastic $N$-player contest, there is at most one active player.

This corollary extends related findings by Hirshleifer (1989), Baik (1997), and Che and Gale (2000).

\section{All-pay auction equilibrium}

To obtain more specific information about the equilibrium set of elastic contests, it is useful to impose some additional structure.

Unless indicated otherwise, a standard contest will refer in this paper to a contest with additively separable payoffs, constant valuations, and linear costs. Thus, without loss of generality, there are valuations $v_{1} \geq v_{2} \geq \ldots \geq$

\footnotetext{
${ }^{16}$ As will be shown further below, for $R$ sufficiently large, any equilibrium (i.e., not necessarily symmetric) of the symmetric $N$-player Tullock contest entails complete rent dissipation.
} 
$v_{N}>0$ such that player $i$ 's payoff function is given by

$$
\Pi_{i}\left(x_{i}, x_{-i}\right)=p_{i}\left(x_{i}, x_{-i}\right) v_{i}-x_{i}
$$

where the contest success function $p_{i}($.$) satisfies the conditions listed in Sec-$ tion 5.3. A standard contest is called anonymous if

$$
p_{i}\left(x_{1}, \ldots, x_{N}\right)=p_{\varphi(i)}\left(x_{\varphi(1)}, \ldots, x_{\varphi(N)}\right)
$$

for any permutation function $\varphi:\{1, \ldots, N\} \rightarrow\{1, \ldots, N\}$. Obviously, in an anonymous contest, if $x_{1}=\ldots=x_{N}$, then each player wins with equal probability $\frac{1}{N} \cdot{ }^{17}$

To characterize the equilibrium set of an elastic anonymous standard contest, the following definition is useful.

Definition 7.1. An all-pay auction equilibrium is a mixed equilibrium such that the following three properties hold:

(A1) Player 1 participates with probability one, invests an average amount of $x_{1}^{*}=\frac{v_{2}}{2}$, wins with probability $p_{1}^{*}=1-\frac{v_{2}}{2 v_{1}}$, and receives a rent of $v_{1}^{*}=v_{1}-v_{2}$. (A2) Player 2 participates with probability $\frac{v_{2}}{v_{1}}$, invests an average amount of $x_{2}^{*}=\frac{\left(v_{2}\right)^{2}}{2 v_{1}}$, wins with probability $p_{2}^{*}=\frac{v_{2}}{2 v_{1}}$, and receives no rent, i.e., $v_{2}^{*}=0$. (A3) All other players $i=3, \ldots, N$ remain purely passive.

Definition 7.1 defines a class of equilibria in imperfectly discriminating contests that share some important descriptive statistics with the equilibrium in the corresponding all-pay auction. It is noted here that in applications, these

\footnotetext{
${ }^{17}$ The class of contests considered by Alcade and Dahm (2010), which is defined through conditions in a discrete setting, corresponds roughly to the class of anonymous elastic standard contests.
} 
statistics are often sufficient to conduct a more extended economic analysis. For example, when the contest is the final stage of a dynamic interaction, then subgame perfection requires only a knowledge of the expected profits from the contest, whereas detailed information about equilibrium strategies is not required.

Sufficient conditions on an imperfectly discriminating contest such that any equilibrium is an all-pay auction equilibrium are provided below. The case of two players is dealt with first.

Theorem 7.2. Any equilibrium in an anonymous elastic two-player standard contest is an all-pay auction equilibrium.

Thus, when there are two contestants, a moderate degree of decisiveness suffices to pin down the equilibrium rents of the players, the probabilities of participation, average bids, as well as the ex-ante winning probabilities. In particular, a definite answer is obtained to the question about the extent of rent dissipation in the two-player Tullock contest with finite decisiveness parameter $R>2$ and potentially heterogeneous valuations.

For more than two players, increasing returns to scale may lead to a coordination problem among players. That is, there may be several mixed equilibria, and depending on the equilibrium, the positive equilibrium rent may go to players other than player 1 . In fact, also the size of the equilibrium rent may depend on the equilibrium. ${ }^{18}$

Theorem 7.3. For $N \geq 3$, there are elastic anonymous standard contests

\footnotetext{
${ }^{18}$ Cornes and Hartley (2005) find multiple pure-strategy equilibria in logit contests with increasing returns. Pure-strategy equilibria, however, are not possible in elastic anonymous standard contests, as follows from Corollary 6.5 in combination with Theorem 7.2.
} 
with multiple mixed equilibria in which both the recipient of the rent and the size of the rent varies with the equilibrium.

The reason for these possibilities is, of course, that the contest is not perfectly discriminating. For example, even if player 1 bids more then the secondhighest valuation $v_{2}<v_{1}$, this does not guarantee that player 1 wins with a sufficiently high probability to make positive payoffs in expected terms. Following this intuition, the rather involved proof of Theorem 7.3 boils down to showing that in an imperfectly discriminating contest, submitting a positive bid may be suboptimal for a player despite having a valuation strictly exceeding that of some active player.

The coordination problem captured by Theorem 7.3 disappears, however, when the contest is sufficiently decisive. To cover the most general conditions under which the all-pay auction has a unique equilibrium, it will be assumed that $v_{2}$ strictly exceeds $v_{3}$, while a weak inequality is allowed between any other neighboring pair of valuations.

Theorem 7.4. Consider an anonymous $N$-player standard contest with valuations $v_{1} \geq v_{2}>v_{3} \geq \ldots \geq v_{N}>0$. Then, provided $\underline{\rho}$ is sufficiently large, any equilibrium is an all-pay auction equilibrium.

Theorem 7.4 strongly supports the robustness of the all-pay auction. To obtain the definite prediction of an all-pay equilibrium, the usual assumption of perfect discrimination can be significantly relaxed. Essential is only that the contest is standard, anonymous, and sufficiently decisive. ${ }^{19}$

\footnotetext{
${ }^{19}$ The elasticity condition can be dropped here because any sufficiently decisive standard contest is elastic by Theorem 5.2. The other assumptions of Theorem 7.4 cannot be relaxed
} 
In the case $v_{1} \geq v_{2}=v_{3} \geq \ldots \geq v_{N}>0$ that is not covered by Theorem 7.4, the all-pay auction allows a continuum of equilibria, which makes the discussion of robustness more difficult. However, in any equilibrium of the all-pay auction, all players with valuations strictly lower than $v_{2}$ remain purely passive, and a positive rent is feasible only for bidders possessing the highest valuation $v_{1}$. These predictions remain true in any equilibrium of a sufficiently decisive anonymous standard contest. Moreover, under the same conditions, as $\underline{\rho}$ grows indefinitely, the profile of rents obtained by bidders in the imperfectly discriminating contest converges to the profile of rents in the all-pay auction equilibrium. Thus, the equilibrium equivalence with its implications for rent dissipation still holds in the limit.

\section{Conclusion}

This paper has proposed a new approach to characterizing the equilibrium set of a large class of imperfectly discriminating contests. For contests in this class, marginal incentives for overbidding are so strong that any positive bid can be rationalized only by smaller positive bids of all competitors. As a consequence, any equilibrium entails either arbitrarily small positive bids or non-participation. In either case, there are immediate and strong implications for the extent of rent dissipation.

The approach used in the analysis has two obvious advantages. First, in contrast to existing approaches, statements about the entire equilibrium set become feasible, which makes the game-theoretic prediction more definitive.

further, however. For example, if the contest is not anonymous, then one player may bid zero with positive probability even with a common valuation. Thus, the prediction of an all-pay auction equilibrium would break down. 
The second advantage is the flexibility of the approach. Restrictions regarding the functional form of the contest, risk neutrality, and unconditional investment all turn out to be of secondary importance. For competitive forces to eliminate rents in a Bertrand fashion, the only essential assumption is that normalized payoffs are elastic. Overall, this may be seen as a further step towards a general theory of contests.

Quite specific results could be obtained for elastic anonymous standard contests. For two players, any equilibrium in such a contest is an all-pay auction equilibrium. This finding corroborates the intuition that preemption is a general property also of many imperfectly discriminating contests. The equivalence extends to three and more players if the contest is, in addition, sufficiently decisive. Thus, the descriptive statistics of the mixed equilibrium in the all-pay auction remains unchanged if the relationship between effort and output is slightly blurred. Rather than assuming a perfectly discriminating contest, it suffices that the contest is standard, anonymous, and sufficiently decisive. This clearly offers some support for the robustness of the all-pay auction. ${ }^{20}$

The analysis has also settled some long-standing open questions regarding Tullock's (1980) rent-seeking game for intermediate values of the decisiveness parameter (i.e., for finite $R>2$ ). ${ }^{21}$

\footnotetext{
${ }^{20}$ For instance, the "exclusion principle" of Baye et al. (1993), which asserts that it may be optimal to exclude the player with the highest valuation from an all-pay auction to increase expected total bids, extends smoothly to the considered class of imperfectly discriminating contests. This observation is not entirely obvious because, as Fang (2002) has shown, the exclusion principle does not extend to the lottery contest.

${ }^{21}$ Further structural properties of the equilibrium bid distribution are derived in a companion paper (2014).
} 


\section{Appendix. Proofs}

Proof of Theorem 5.1. The proof checks the conditions of Definition 4.2 for the difference-form payoff function (13), starting with (L1). Consider bid levels $x_{i}^{0}>0$ and $x_{j}^{0}>0$. By exchanging the roles of $i$ and $j$, if necessary, one may assume without loss of generality that $x_{i}^{0} \leq x_{j}^{0}$. Differentiating the normalized payoff-function,

$$
\Pi_{i}\left(x_{i}, x_{j}\right)=\left(F\left(x_{i}-x_{j}\right)-F\left(-x_{j}\right)\right) v_{i}-x_{i}
$$

with respect to $x_{i}$ yields

$$
\frac{\partial \Pi_{i}}{\partial x_{i}}=f\left(x_{i}-x_{j}\right) v_{i}-1 .
$$

Using (25) and (26), inequality (10) becomes

$$
f\left(x_{i}^{0}-x_{j}\right) v_{i}-1>\lambda\left\{\left(F\left(x_{i}^{0}-x_{j}\right)-F\left(-x_{j}\right)\right) v_{i}-x_{i}\right\}
$$

Letting $\lambda=1 / x_{i}^{0}$, and noting that $v_{i}>0$, inequality $(27)$ reduces to

$$
f\left(x_{i}^{0}-x_{j}\right) x_{i}^{0}>F\left(x_{i}^{0}-x_{j}\right)-F\left(-x_{j}\right) .
$$

To verify (L1), it suffices to show that inequality (28) holds for any $x_{j} \geq x_{j}^{0}$. Consider some arbitrary $x_{j} \geq x_{j}^{0}$. Clearly,

$$
-x_{j}+x_{j}^{0} \leq-x_{j}^{0}+x_{j}^{0} \leq 0 .
$$

Moreover, since the density $f_{i}($.$) is hump-shaped with mode zero, f_{i}(z)$ is strictly increasing when $z \leq 0$. Therefore, since $x_{i}^{0}>0$,

$$
\begin{aligned}
f\left(-x_{j}+x_{i}^{0}\right) x_{i}^{0} & =f\left(-x_{j}+x_{i}^{0}\right) \int_{-x_{j}}^{-x_{j}+x_{i}^{0}} d z \\
& >\int_{-x_{j}}^{-x_{j}+x_{i}^{0}} f(z) d z \\
& =F\left(-x_{j}+x_{i}^{0}\right)-F\left(-x_{j}\right) .
\end{aligned}
$$


This proves (L1). Further, for $x_{i}^{0}>0$ sufficiently small given $x_{j}^{0}>0$, the exchange of $i$ and $j$ is not necessary to derive $x_{i}^{0} \leq x_{j}^{0}$, which verifies condition (L2). In sum, this proves the theorem.

Proof of Theorem 5.2. The proof of the first assertion in the statement of the theorem verifies the two conditions of Definitions 4.2 for additively separable payoff functions. To check condition (L1), let $x_{i}^{0}>0$ and $x_{j}^{0}>0$. Using the notation $\left(x_{i}, x_{-i}\right)=\left(x_{i}, x_{j}, x_{-i, j}\right)$, the payoff function (16) can be rewritten as

$$
\Pi_{i}\left(x_{i}, x_{j}, x_{-i, j}\right)=p_{i}\left(x_{i}, x_{j}, x_{-i, j}\right) V_{i}\left(x_{i}, x_{j}, x_{-i, j}\right)-C_{i}\left(x_{i}, x_{j}, x_{-i, j}\right),
$$

Differentiating (33) with respect to $x_{i}$ yields

$$
\begin{aligned}
& \frac{\partial \prod_{i}\left(x_{i}, x_{j}, x_{-i, j}\right)}{\partial x_{i}}=\frac{\partial p_{i}\left(x_{i}, x_{j}, x_{-i, j}\right)}{\partial x_{i}} V_{i}\left(x_{i}, x_{j}, x_{-i, j}\right) \\
& \quad+p_{i}\left(x_{i}, x_{j}, x_{-i, j}\right) \frac{\partial V_{i}\left(x_{i}, x_{j}, x_{-i, j}\right)}{\partial x_{i}}-\frac{\partial C_{i}\left(x_{i}, x_{j}, x_{-i, j}\right)}{\partial x_{i}} .
\end{aligned}
$$

Plugging these expressions into inequality (10), one obtains

$$
\begin{aligned}
\frac{\partial p_{i}\left(x_{i}^{0}, x_{j}, x_{-i, j}\right)}{\partial x_{i}} V_{i}\left(x_{i}^{0}, x_{j}, x_{-i, j}\right)+p_{i}\left(x_{i}^{0}, x_{j}, x_{-i, j}\right) \frac{\partial V_{i}\left(x_{i}^{0}, x_{j}, x_{-i, j}\right)}{\partial x_{i}} \\
\quad-\frac{\partial C_{i}\left(x_{i}^{0}, x_{j}, x_{-i, j}\right)}{\partial x_{i}} \\
>\lambda\left(p_{i}\left(x_{i}^{0}, x_{j}, x_{-i, j}\right) V_{i}\left(x_{i}^{0}, x_{j}, x_{-i, j}\right)-C_{i}\left(x_{i}^{0}, x_{j}, x_{-i, j}\right)\right) .
\end{aligned}
$$

For

$$
\lambda=\frac{\partial C_{i}\left(x_{i}^{0}, x_{j}, x_{-i, j}\right) / \partial x_{i}}{C_{i}\left(x_{i}^{0}, x_{j}, x_{-i, j}\right)}
$$

inequality (35) is equivalent to

$$
\frac{\partial p_{i}\left(x_{i}^{0}, x_{j}, x_{-i, j}\right) / \partial x_{i}}{p_{i}\left(x_{i}^{0}, x_{j}, x_{-i, j}\right)}+\frac{\partial V_{i}\left(x_{i}^{0}, x_{j}, x_{-i, j}\right) / \partial x_{i}}{V_{i}\left(x_{i}^{0}, x_{j}, x_{-i, j}\right)}>\frac{\partial C_{i}\left(x_{i}^{0}, x_{j}, x_{-i, j}\right) / \partial x_{i}}{C_{i}\left(x_{i}^{0}, x_{j}, x_{-i, j}\right)}
$$


Using the notation introduced before the statement of the theorem, inequality (37) can be rewritten as

$$
\rho_{i}\left(x_{i}^{0}, x_{j}, x_{-i, j}\right)\left(1-p_{i}\left(x_{i}^{0}, x_{j}, x_{-i, j}\right)\right)+\alpha_{i}\left(x_{i}^{0}, x_{j}, x_{-i, j}\right)>\gamma_{i}\left(x_{i}^{0}, x_{j}, x_{-i, j}\right) .
$$

Now, since the contest success function is monotone, and since $x_{j} \geq x_{j}^{0}$,

$$
p_{i}\left(x_{i}^{0}, x_{j}, x_{-i, j}\right) \leq p_{i}\left(x_{i}^{0}, x_{j}^{0}, x_{-i, j}\right) \leq p_{i}\left(x_{i}^{0}, x_{j}^{0}, 0_{-i, j}\right)
$$

where $0_{-i, j}$ denotes a vector with $N-2$ zero entries. Clearly, either

$$
p_{i}\left(x_{i}^{0}, x_{j}^{0}, 0_{-i, j}\right) \leq \frac{1}{2}
$$

or

$$
p_{j}\left(x_{j}^{0}, x_{i}^{0}, 0_{-i, j}\right)=1-p_{i}\left(x_{i}^{0}, x_{j}^{0}, 0_{-i, j}\right)<\frac{1}{2},
$$

so that, possibly after exchanging the roles of $i$ and $j$,

$$
p_{i}\left(x_{i}^{0}, x_{j}, x_{-i, j}\right) \leq \frac{1}{2}
$$

for any $x_{j} \geq x_{j}^{0}$ and any $x_{-i, j} \in X_{-i, j}$. Using $\underline{\rho}>2(\bar{\gamma}-\underline{\alpha})$, this shows that inequality (38) holds for any $x_{j} \geq x_{j}^{0}$ and any $x_{-i, j} \in X_{-i, j}$, which establishes condition (L1). As for (L2), note that, since a zero bid never wins against a positive bid, and since $x_{j}^{0}>0$, it must be that $p_{i}\left(0, x_{j}^{0}, 0_{-i, j}\right)=0$. Therefore, using the continuity of the contest success function at non-zero bid vectors, inequality (40) holds also if $x_{i}^{0}>0$ is made sufficiently small given $x_{j}^{0}>0$. This proves also (L2), and therefore, the first assertion in the statement of the theorem. As for the second assertion, note that in the symmetric case, by the monotonicity of the contest success function,

$$
p_{i}\left(x_{i}^{0}, x_{-i}\right) \leq p_{i}\left(x_{i}^{0}, x_{i}^{0}, \ldots, x_{i}^{0}\right)=\frac{1}{N}
$$


for any $x_{i}^{0}>0$, and for any $x_{-i}$ satisfying $x_{j} \geq x_{i}^{0}$ for all $j \neq i$. Therefore, provided that $\underline{\rho}>\frac{N}{N-1}(\bar{\gamma}-\underline{\alpha})$, the condition of Definition 4.1 can be verified just as in the first part of the proof.

Proof of Theorem 5.3. The proof verifies that the payoff function (21) satisfies the conditions of Definition 4.2. Dropping the arguments, player $i$ 's expected utility can be written as

$$
\Pi_{i}=u_{i}\left(w_{i}-x_{i}\right)+p_{i} \Delta u_{i}
$$

where

$$
\Delta u_{i}=u_{i}\left(w_{i}+v_{i}-x_{i}\right)-u_{i}\left(w_{i}-x_{i}\right)>0 .
$$

Differentiating (44) with respect to $x_{i}$ yields

$$
\frac{\partial \prod_{i}}{\partial x_{i}}=-u_{i}^{\prime}\left(w_{i}-x_{i}\right)+\frac{\partial p_{i}}{\partial x_{i}} \Delta u_{i}-p_{i} \Delta u_{i}^{\prime}
$$

where

$$
\Delta u_{i}^{\prime}=u_{i}^{\prime}\left(w_{i}+v_{i}-x_{i}\right)-u_{i}^{\prime}\left(w_{i}-x_{i}\right) \leq 0 .
$$

To verify conditions (L1) and (L2), consider the inequality

$$
\frac{\partial \Pi_{i}\left(x_{i}^{0}, x_{j}, x_{-i, j}\right)}{\partial x_{i}}>\lambda \Pi_{i}\left(x_{i}^{0}, x_{j}, x_{-i, j}\right) .
$$

Plugging (44) and (46) into inequality (48) yields

$$
-u_{i}^{\prime}\left(w_{i}-x_{i}^{0}\right)+\frac{\partial p_{i}}{\partial x_{i}} \Delta u_{i}-p_{i} \Delta u_{i}^{\prime}>\lambda\left(u_{i}\left(w_{i}-x_{i}^{0}\right)+p_{i} \Delta u_{i}\right) .
$$

Since $u_{i}\left(w_{i}\right)=0$ and $x_{i}^{0}>0$, one may choose

$$
\lambda=\lambda\left(x_{i}^{0}\right)=\frac{u_{i}^{\prime}\left(w_{i}-x_{i}^{0}\right)}{\left|u_{i}\left(w_{i}-x_{i}^{0}\right)\right|}>0,
$$


so that (49) simplifies into

$$
x_{i}^{0} \frac{\partial p_{i} / \partial x_{i}}{p_{i}}-x_{i}^{0} \frac{\Delta u_{i}^{\prime}}{\Delta u_{i}}>x_{i}^{0} \frac{u_{i}^{\prime}\left(w_{i}-x_{i}^{0}\right)}{\left|u_{i}\left(w_{i}-x_{i}^{0}\right)\right|} .
$$

Note that the second term on the left-hand side of (51) is positive as a consequence of weak risk aversion. Therefore, a sufficient condition for (48) is

$$
x_{i}^{0} \frac{\partial p_{i} / \partial x_{i}}{p_{i}}>\frac{x_{i}^{0} u_{i}^{\prime}\left(w_{i}-x_{i}^{0}\right)}{\left|u_{i}\left(w_{i}-x_{i}^{0}\right)\right|} .
$$

Since $u_{i}\left(w_{i}\right)=0$, and $u_{i}($.$) is concave, \left|u_{i}\left(w_{i}-x_{i}^{0}\right)\right| \geq x_{i}^{0} u_{i}^{\prime}\left(w_{i}\right)$. Therefore, the right-hand side of inequality (52) can be bounded from above as follows:

$$
\begin{aligned}
\frac{x_{i}^{0} u_{i}^{\prime}\left(w_{i}-x_{i}^{0}\right)}{\left|u_{i}\left(w_{i}-x_{i}^{0}\right)\right|} & \leq \frac{u_{i}^{\prime}\left(w_{i}-x_{i}^{0}\right)}{u_{i}^{\prime}\left(w_{i}\right)} \\
& =\exp \left(-\int_{w_{i}-x_{i}^{0}}^{w_{i}} \frac{u_{i}^{\prime \prime}(z)}{u_{i}^{\prime}(z)} d z\right) \\
& =\exp \left(\int_{w_{i}-x_{i}^{0}}^{w_{i}} \eta(z) d z\right) \\
& \leq \exp \left(v_{i} \bar{\eta}\right) \\
& \leq \exp \left(v_{1} \bar{\eta}\right)
\end{aligned}
$$

Thus, using

$$
x_{i}^{0} \frac{\partial p_{i} / \partial x_{i}}{p_{i}}=\rho_{i}\left(x_{i}^{0}, x_{j}, x_{-i, j}\right)\left(1-p_{i}\left(x_{i}^{0}, x_{j}, x_{-i, j}\right)\right),
$$

a sufficient condition for inequality (48) is

$$
\rho_{i}\left(x_{i}^{0}, x_{j}, x_{-i, j}\right)\left(1-p_{i}\left(x_{i}^{0}, x_{j}, x_{-i, j}\right)\right)>\exp \left(v_{1} \bar{\eta}\right) .
$$

In analogy to condition (38) in the proof of Theorem 5.2, condition (59) ensures now that conditions (L1) and (L2) in Definition 4.2 hold, which concludes the proof of the theorem. 
Proof of Lemma 6.1. The proof is by contradiction. Consider a mixed equilibrium $\left(\mu_{1}^{*}, \ldots, \mu_{N}^{*}\right)$, and suppose there are players $j \neq i$ such that $\mu_{i}^{*}(\{0\})=0$ and $\underline{x}_{j}>0$. If also $\underline{x}_{i}>0$, then from condition (L1) in Definition 4.2, there exists some $\lambda>0$ such that, possibly after exchanging the roles of $i$ and $j$,

$$
\frac{\partial \prod_{i}}{\partial x_{i}}\left(\underline{x}_{i}, x_{j}, x_{-i, j}\right)>\lambda \Pi_{i}\left(\underline{x}_{i}, x_{j}, x_{-i, j}\right)
$$

holds for any $x_{j} \geq \underline{x}_{j}$ and for any $x_{-i, j} \in X_{-i, j}$. Integrating inequality (60) over $X_{-i}$ yields

$$
\int \frac{\partial \Pi_{i}}{\partial x_{i}}\left(\underline{x}_{i}, x_{-i}\right) d \mu_{-i}^{*}\left(x_{-i}\right)>\lambda \int \Pi_{i}\left(\underline{x}_{i}, x_{-i}\right) d \mu_{-i}^{*}\left(x_{-i}\right)
$$

Moreover, the lowest bid $\underline{x}_{i}$ is positive and, hence, optimal. Therefore,

$$
\int \Pi_{i}\left(\underline{x}_{i}, x_{-i}\right) d \mu_{-i}^{*}\left(x_{-i}\right) \geq \int \Pi_{i}\left(0, x_{-i}\right) d \mu_{-i}^{*}\left(x_{-i}\right)
$$

Finally, since payoffs are normalized and $\underline{x}_{j}>0$,

$$
\int \Pi_{i}\left(0, x_{-i}\right) d \mu_{-i}^{*}\left(x_{-i}\right)=0
$$

Combining (61) through (63), one arrives at

$$
\int \frac{\partial \Pi_{i}}{\partial x_{i}}\left(\underline{x}_{i}, x_{-i}\right) d \mu_{-i}^{*}\left(x_{-i}\right)>0
$$

which contradicts $\underline{x}_{i} \in S\left(\mu_{i}^{*}\right)$. Thus, there cannot be players $i \neq j$ such that $\underline{x}_{i}>0$ and $\underline{x}_{j}>0$, proving the assertion in this case. If $\underline{x}_{i}=0$ and $\mu_{i}(\{0\})=0$ then $\underline{x}_{i}^{+}=0$. Hence, from condition (L2) in Definition 4.2, for any sufficiently small $x_{i} \in S\left(\mu_{i}^{*}\right) \backslash\{0\}$, there exists some $\lambda>0$ such that

$$
\frac{\partial \prod_{i}}{\partial x_{i}}\left(x_{i}, x_{j}, x_{-i, j}\right)>\lambda \Pi_{i}\left(x_{i}, x_{j}, x_{-i, j}\right)
$$


holds for any $x_{j} \geq \underline{x}_{j}$ and for any $x_{-i, j} \in X_{-i, j}$. The proof now proceeds as in the first case, with $\underline{x}_{i}$ replaced by $x_{i}$.

Proof of Lemma 6.2. Assume that $\mu_{i}^{*}(\{0\})=0$, and fix some player $j \neq i$. Lemma 6.1 implies that $\underline{x}_{j}=0$. Clearly, $\Pi_{j}^{*}=0$ if player $j$ bids zero with positive probability. Assume, therefore, that $\mu_{j}^{*}(\{0\})=0$. Then, $\underline{x}_{j}^{+}=0$. Player $j$ 's expected payoffs from bidding some $x_{j} \in S\left(\mu_{j}^{*}\right)$ are given by

$$
\Pi_{j}^{*}=\int_{X_{-j}} \Pi_{j}\left(x_{j}, x_{-j}\right) d \mu_{-j}^{*}\left(x_{-j}\right)
$$

Fix $\varepsilon>0$. Define the set of bid vectors in which bidder $i$ 's bid weakly exceeds $\varepsilon$, i.e.,

$$
X_{-j}(\varepsilon)=\left\{\left(x_{i}, x_{-i, j}\right) \in X_{i} \times X_{-i, j}: x_{i} \geq \varepsilon\right\},
$$

Player $j$ 's expected payoffs (66) are now decomposed according to whether bidder $i$ 's bid weakly exceeds $\varepsilon$ or not. Thus,

$$
\Pi_{j}^{*}=\int_{X_{-j} \backslash X_{-j}(\varepsilon)} \Pi_{j}\left(x_{j}, x_{-j}\right) d \mu_{-j}^{*}\left(x_{-j}\right)+\int_{X_{-j}(\varepsilon)} \Pi_{j}\left(x_{j}, x_{-j}\right) d \mu_{-j}^{*}\left(x_{-j}\right) .
$$

Since the set function $\mu_{i}^{*}$ is a probability measure, it is continuous from above. Hence, $\mu_{i}^{*}([0, \varepsilon])$ becomes arbitrarily small for $\varepsilon$ small. In particular, because payoffs are bounded from above, the first integral in (68) can be made arbitrarily small by a suitable choice of $\varepsilon>0$. As for the second integral in (68), note that $X_{-j}(\varepsilon)$ does not contain the origin, so that $\Pi_{j}\left(x_{j}, x_{-j}\right)$ is continuous on $X_{-j}(\varepsilon)$. In particular, for any $x_{-j} \in X_{-j}(\varepsilon)$,

$$
\lim _{x_{j} \rightarrow 0} \Pi_{j}\left(x_{j}, x_{-j}\right)=\Pi_{j}\left(0, x_{-j}\right)=0 .
$$

Clearly, $X_{-j}(\varepsilon)$ is a bounded and closed set. Therefore, invoking Lebesgue's Theorem of Bounded Convergence, limit and integral may be exchanged. 
Thus,

$$
\lim _{x_{j} \rightarrow 0} \int_{X_{-j}(\varepsilon)} \Pi_{j}\left(x_{j}, x_{-j}\right) d \mu_{-j}^{*}\left(x_{-j}\right)=\int_{X_{-j}(\varepsilon)} \lim _{x_{j} \rightarrow 0} \Pi_{j}\left(x_{j}, x_{-j}\right) d \mu_{-j}^{*}\left(x_{-j}\right)=0 .
$$

Hence, by first choosing $\varepsilon>0$ sufficiently small, and then some positive $x_{j} \in S\left(\mu_{j}^{*}\right)$ sufficiently small, the integral (66) can be made smaller than any strictly positive bound. Thus, $\Pi_{j}^{*}=0$, which concludes the proof.

Proof of Theorem 6.3. If $\Pi_{i}^{*}=0$ for all players $i$, then there is nothing to show. Assume, therefore, that there is some player $i$ with $\Pi_{i}^{*}>0$. Then, participation is strictly profitable, so that $\mu_{i}^{*}(\{0\})=0$. Then, however, Lemma 6.2 implies that $\Pi_{j}^{*}=0$ for any $j \neq i$. This proves the assertion.

Proof of Corollary 6.4. Immediate from Theorem 6.3.

Proof of Corollary 6.5. Immediate from Lemma 6.1.

Proof of Theorem 7.2. Assume first that some player $i$ is always active. Let $j \neq i$, and write $q=\mu_{j}^{*}(\{0\})$. If $q=1$, then player $i$ wins with probability one, and therefore could strictly benefit by shading all his bids, which is impossible in equilibrium. Therefore, $0 \leq q<1$. Consider the modified contest in which player $i$ 's valuation is scaled down to $v_{i}^{\prime}=v_{i} \cdot(1-q)>0$. Recall that player $j$ 's mixed strategy $\mu_{j}^{*}$ is a real-valued set function defined on the collection of Borel subsets of the interval $X_{j}$. Therefore, for any Borel set $Y_{j} \subseteq X_{j}$, the probability that player $j$ chooses a nonzero strategy from the set $Y_{j}$ may be written as $\mu_{j}^{*}\left(Y_{j} \backslash\{0\}\right)$. Define now a mixed strategy $\widehat{\mu}_{j}$ in the modified contest via

$$
\widehat{\mu}_{j}\left(Y_{j}\right)=\frac{\mu_{j}^{*}\left(Y_{j} \backslash\{0\}\right)}{1-q}
$$


for any Borel set $Y_{j} \subseteq X_{j}$. It is easy to check that $\left(\mu_{i}^{*}, \widehat{\mu}_{j}\right)$ is an equilibrium in the modified contest. Note that $\widehat{\mu}_{j}$ does not entail zero bids. Therefore, from Lemma 6.2, there is full rent dissipation in this equilibrium for both players. Applying Lemma A.1 to the equilibrium in the modified contest yields that $v_{i}^{\prime}=v_{j}$. Hence, using $v_{i}^{\prime}=v_{i} \cdot(1-q)$, it follows that $\mu_{j}^{*}(\{0\})=\frac{v_{i}-v_{j}}{v_{i}}$, which implies that $i=1$ and $j=2$. Moreover, since both players win with equal probability in the modified contest, player 1 realizes a rent of $v_{1}-v_{2}$ in the original contest, as claimed. Thus, any equilibrium with two players is payoff-equivalent to an all-pay auction equilibrium. If $\mu_{i}^{*}(\{0\})>0$ for both players $i=1,2$, then there is full rent dissipation and the argument goes through as above (for $q=0$ ). The remaining assertions are now immediate.

The following lemma is used in the proof of Theorem 7.2.

Lemma A.1. Consider an anonymous two-player standard contest. If $\Pi_{1}^{*}=$ $\Pi_{2}^{*}=0$, then $v_{1}=v_{2}$ and $p_{1}^{*}=p_{2}^{*}=\frac{1}{2}$.

Proof. Assume that

$$
\begin{aligned}
& p_{1}^{*} v_{1}-x_{1}^{*}=0, \\
& p_{2}^{*} v_{2}-x_{2}^{*}=0,
\end{aligned}
$$

where $p_{i}^{*}$ is player $i$ 's ex-ante expected probability of winning, and $x_{i}^{*}$ is player $i$ 's ex-ante expected bid. Suppose now that player 2 considers copying player 1 's strategy $\mu_{1}^{*}$. Since expected payoffs are zero for player 2 in equilibrium, a deviation to $\mu_{1}^{*}$ would necessarily yield weakly negative expected payoffs for 
player 2, i.e.,

$$
\frac{1}{2} v_{2}-x_{1}^{*} \leq 0
$$

where the winning probability of $\frac{1}{2}$ follows from anonymity. Similarly,

$$
\frac{1}{2} v_{1}-x_{2}^{*} \leq 0
$$

It is now easy to see that (72-75) imply

$$
\begin{aligned}
& p_{2}^{*} v_{2} \geq \frac{1}{2} v_{1}, \\
& p_{1}^{*} v_{1} \geq \frac{1}{2} v_{2} .
\end{aligned}
$$

Adding up yields

$$
p_{1}^{*} v_{1}+p_{2}^{*} v_{2} \geq \frac{v_{1}+v_{2}}{2} .
$$

Suppose $v_{1}>v_{2}$. Then $p_{2}^{*} \leq \frac{1}{2}$. But from $v_{1}>v_{2}$, and (76), $p_{2}^{*}>\frac{1}{2}$, which is a contradiction. Similarly, $v_{1}<v_{2}$ leads to a contradiction. Hence, $v_{1}=v_{2}$. In particular, (78) is an equality, so each of (76) and (77) must be equalities. Thus, also $p_{1}^{*}=p_{2}^{*}=\frac{1}{2}$.

Proof of Theorem 7.3. Consider a three-player Tullock contest with decisiveness parameter $R>2$ and valuations $v_{1}>v_{2}>v_{3}>0$. Alcade and Dahm (2010) have constructed an all-pay auction equilibrium in which player 1 earns a positive rent. To prove the first claim in the statement of the theorem, it will be shown now that, provided $v_{1}, v_{2}$, and $v_{3}$ are sufficiently close to each other, there exist another equilibrium in which player 2 earns a positive rent. For this, take an all-pay auction equilibrium $\left(\mu_{2}^{*}, \mu_{3}^{*}\right)$ in the two-player contest between players 2 and 3. It suffices to verify that player 1's expected 
payoff from entering with some positive bid $x_{1}>0$ is negative. If matched in a two-player contest against $\mu_{2}^{*}$, the bid $x_{1}$ wins with probability

$$
p_{12}=\int \frac{x_{1}^{R}}{x_{1}^{R}+x_{2}^{R}} d \mu_{2}^{*}\left(x_{2}\right)>0 .
$$

Denote player 1's rent from playing $x_{1}$ against $\mu_{2}^{*}$ in the two-player contest by $\Pi_{12}^{*}=p_{12} v_{1}-x_{1}$. I claim that

$$
\Pi_{12}^{*} \leq p_{12} \cdot\left(v_{1}-v_{3}\right)
$$

where the right-hand side of (80) corresponds intuitively to player 1's excess rent, compared to player 3 in the same situation. Suppose inequality (80) does not hold. Then, in the two-player contest between 2 and 3, player 3 could submit a bid equal to $x_{1}$ (instead of playing $\mu_{3}^{*}$ ), and thereby realize a rent of

$$
p_{12} v_{3}-x_{1}=p_{12} v_{1}-x_{1}-p_{12} \cdot\left(v_{1}-v_{3}\right)>0 \text {. }
$$

This, however, contradicts the fact that player 3's rent is completely dissipated in the two-player all-pay auction equilibrium $\left(\mu_{2}^{*}, \mu_{3}^{*}\right)$. Thus, inequality (80) indeed holds. Note next that player 1's rent from bidding $x_{1}$ against $\mu_{2}^{*}$ is diminished if player 3's bidding is taken into account. Specifically, in the all-pay auction equilibrium $\left(\mu_{2}^{*}, \mu_{3}^{*}\right)$, player 3 exerts an average effort of

$$
\int x_{3} d \mu_{3}^{*}\left(x_{3}\right)=\frac{v_{3}^{2}}{2 v_{2}}
$$


Hence, on average, player 1's probability of winning is lowered by

$$
\begin{aligned}
& \int\left(\frac{x_{1}^{R}}{x_{1}^{R}+x_{2}^{R}}-\frac{x_{1}^{R}}{x_{1}^{R}+x_{2}^{R}+x_{3}^{R}}\right) d\left(\mu_{2}^{*}\left(x_{2}\right) \times \mu_{3}^{*}\left(x_{3}\right)\right) \\
& =\int \frac{x_{1}^{R}}{x_{1}^{R}+x_{2}^{R}}\left(1-\frac{x_{1}^{R}+x_{2}^{R}}{x_{1}^{R}+x_{2}^{R}+x_{3}^{R}}\right) d\left(\mu_{2}^{*}\left(x_{2}\right) \times \mu_{3}^{*}\left(x_{3}\right)\right) \\
& =\int \frac{x_{1}^{R}}{x_{1}^{R}+x_{2}^{R}}\left\{\int \frac{x_{3}^{R}}{x_{1}^{R}+x_{2}^{R}+x_{3}^{R}} d \mu_{3}^{*}\left(x_{3}\right)\right\} d \mu_{2}^{*}\left(x_{2}\right) \\
& \geq \frac{1}{3 v_{1}^{R}} \cdot \int \frac{x_{1}^{R}}{x_{1}^{R}+x_{2}^{R}} d \mu_{2}^{*}\left(x_{2}\right) \cdot \int x_{3}^{R} d \mu_{3}^{*}\left(x_{3}\right) \\
& \geq \frac{1}{3 v_{1}^{R}} \cdot p_{12} \cdot\left(\int x_{3} d \mu_{3}^{*}\left(x_{3}\right)\right)^{R} \\
& =\frac{1}{3 v_{1}^{R}} \cdot p_{12} \cdot\left(\frac{v_{3}^{2}}{2 v_{2}}\right)^{R},
\end{aligned}
$$

where Jensen's inequality has been used. Therefore, player 1's rent from bidding $x_{1}$ in the three-player contest against $\mu_{2}^{*}$ and $\mu_{3}^{*}$ is

$$
\begin{gathered}
\int\left(\frac{x_{1}^{R}}{x_{1}^{R}+x_{2}^{R}+x_{3}^{R}}-x_{1}\right) d\left(\mu_{2}^{*}\left(x_{2}\right) \times \mu_{3}^{*}\left(x_{3}\right)\right) \\
\leq p_{12} \cdot\left\{v_{1}-v_{3}-\frac{1}{3 v_{1}^{R}}\left(\frac{v_{3}^{2}}{2 v_{2}}\right)^{R} v_{1}\right\}
\end{gathered}
$$

Assume now that players' valuations are very close to each other, so that

$$
\frac{v_{3}}{v_{1}} \geq\left(1-\frac{1}{2^{R+3}}\right)^{1 / 2 R}
$$

Then, since $R>2$,

$$
\frac{v_{3}}{v_{1}}>1-\frac{1}{2^{R+3}}
$$

so that

$$
v_{1}-v_{3}<\frac{v_{1}}{2^{R+3}}
$$

On the other hand,

$$
\frac{1}{3 v_{1}^{R}}\left(\frac{v_{3}^{2}}{2 v_{2}}\right)^{R}>\frac{1}{2^{R+2}}\left(\frac{v_{3}^{2}}{v_{1}^{2}}\right)^{R} \geq \frac{1}{2^{R+2}}\left(1-2^{-(R+3)}\right)>\frac{1}{2^{R+3}} .
$$


Combining (91) and (92) shows that, if (89) holds, the right-hand side of inequality (88) is negative, which proves the first claim in the statement of the theorem. To prove the second claim, consider an all-pay auction equilibrium in the two-player contest between players 1 and 3 , and note that, as above, player 2 has no incentive to submit a positive bid if the three valuations are sufficiently close to each other. Then, player 1 earns a rent of $v_{1}-v_{3} \neq v_{1}-v_{2}$. Thus, player 1's rent may depend on the equilibrium. This proves the second claim, and thereby the theorem.

Proof of Theorem 7.4. The proof is by contradiction. Let $i \in\{1,2\}$, and suppose that some player $j \in\{3, \ldots, N\}$ is active. Then, the highest bid used by player $j$ is positive, i.e., $\bar{x}_{j}>0$. By the anonymity and monotonicity of the contest success function,

$$
p_{i}\left(\bar{x}_{j}, 0, x_{-i, j}\right)=p_{j}\left(\bar{x}_{j}, 0, x_{-i, j}\right) \geq p_{j}\left(\bar{x}_{j}, x_{i}, x_{-i, j}\right),
$$

for any $x_{i} \in X_{i}$ and any $x_{-i, j} \in X_{-i, j}$. Moreover, since $\bar{x}_{j}$ is optimal, and a zero bid always guarantees a weakly positive payoff,

$$
\int p_{j}\left(\bar{x}_{j}, x_{i}, x_{-i, j}\right) d\left(\mu_{i}^{*}\left(x_{i}\right) \times \mu_{-i, j}^{*}\left(x_{-i, j}\right)\right) v_{j}-\bar{x}_{j} \geq 0 .
$$

Combining (93) and (94), and subsequently integrating $x_{i}$ out, yields

$$
\int p_{i}\left(\bar{x}_{j}, 0, x_{-i, j}\right) d \mu_{-i, j}^{*}\left(x_{-i, j}\right) v_{j}-\bar{x}_{j} \geq 0 .
$$

By assumption, $v_{i} \geq v_{2}>v_{3} \geq v_{j}$. Therefore,

$$
\kappa \equiv \sqrt{\frac{v_{i}}{v_{j}}}>1 .
$$

Hence, $v_{j}=v_{i} / \kappa^{2}$ and therefore

$$
\int \frac{p_{i}\left(\bar{x}_{j}, 0, x_{-i, j}\right)}{\kappa} d \mu_{-i, j}^{*}\left(x_{-i, j}\right) v_{i}-\kappa \bar{x}_{j} \geq 0 .
$$


By Lemmata A.2 and A.3, provided that $\rho$ is sufficiently large,

$$
\frac{p_{i}\left(\bar{x}_{j}, 0, x_{-i, j}\right)}{\kappa} \leq \frac{2}{\kappa} p_{i}\left(\bar{x}_{j}, \bar{x}_{j}, x_{-i, j}\right)<p_{i}\left(\kappa \bar{x}_{j}, \bar{x}_{j}, x_{-i, j}\right)
$$

for any $x_{-i, j} \in X_{-i, j}$. Combining (97) and (98), one finds

$$
\int p_{i}\left(\kappa \bar{x}_{j}, \bar{x}_{j}, x_{-i, j}\right) d \mu_{-i, j}^{*}\left(x_{-i, j}\right) v_{i}-\kappa \bar{x}_{j}>0 .
$$

By the monotonicity of the contest success function,

$$
p_{i}\left(\kappa \bar{x}_{j}, \bar{x}_{j}, x_{-i, j}\right) \leq p_{i}\left(\kappa \bar{x}_{j}, x_{j}, x_{-i, j}\right)
$$

for any $x_{j} \in S\left(\mu_{j}^{*}\right)$ and any $x_{-i, j} \in X_{-i, j}$. Hence, combining the last two inequalities, and subsequently integrating over $X_{j}$, yields

$$
\int p_{i}\left(\kappa \bar{x}_{j}, x_{j}, x_{-i, j}\right) d\left(\mu_{j}^{*}\left(x_{j}\right) \times \mu_{-i, j}^{*}\left(x_{-i, j}\right)\right) v_{i}-\kappa \bar{x}_{j}>0 .
$$

I.e., player $i$ receives positive payoffs from unilaterally playing $x_{i}=\kappa \bar{x}_{j}$ with certainty. It follows that both players, 1 and 2, earn positive rents. But this is impossible in view of Theorem 6.3. Hence, players $j=3, \ldots, N$ are indeed all purely passive. The assertion now follows from Theorem 7.2.

The following two lemmata are used in the proof of Theorem 7.4.

Lemma A.2. Fix $\kappa>1$. Then, for any sufficiently large $\underline{\rho}$,

$$
p_{i}\left(\kappa \bar{x}_{j}, \bar{x}_{j}, x_{-i, j}\right)>\frac{2}{\kappa} p_{i}\left(\bar{x}_{j}, \bar{x}_{j}, x_{-i, j}\right)
$$

for any $x_{-i, j} \in X_{-i, j}$.

Proof. The proof is by contradiction. Suppose that

$$
p_{i}\left(\kappa \bar{x}_{j}, \bar{x}_{j}, x_{-i, j}\right) \leq \frac{2}{\kappa} p_{i}\left(\bar{x}_{j}, \bar{x}_{j}, x_{-i, j}\right)
$$


for some $x_{-i, j} \in X_{-i, j}$. Then, since anonymity implies $p_{i}\left(\bar{x}_{j}, \bar{x}_{j}, x_{-i, j}\right) \leq \frac{1}{2}$, necessarily

$$
p_{i}\left(\kappa \bar{x}_{j}, \bar{x}_{j}, x_{-i, j}\right) \leq \frac{1}{\kappa}
$$

By monotonicity,

$$
p_{i}\left(\tilde{\kappa} \bar{x}_{j}, \bar{x}_{j}, x_{-i, j}\right) \leq \frac{1}{\tilde{\kappa}}
$$

for any $\tilde{\kappa} \in[1, \kappa]$. As a consequence, the own-bid elasticity of the contest success function satisfies

$$
\begin{aligned}
\tau_{i}\left(\tilde{\kappa} \bar{x}_{j}, \bar{x}_{j}, x_{-i, j}\right) & \equiv\left(1-p_{i}\left(\tilde{\kappa} \bar{x}_{j}, \bar{x}_{j}, x_{-i, j}\right)\right) \rho_{i}\left(\tilde{\kappa} \bar{x}_{j}, \bar{x}_{j}, x_{-i, j}\right) \\
& \geq\left(1-\frac{1}{\tilde{\kappa}}\right) \underline{\rho}
\end{aligned}
$$

for any $\tilde{\kappa} \in[1, \kappa]$. Hence,

$$
\begin{aligned}
\frac{p_{i}\left(\kappa \bar{x}_{j}, \bar{x}_{j}, x_{-i, j}\right)}{p_{i}\left(\bar{x}_{j}, \bar{x}_{j}, x_{-i, j}\right)} & =\exp \int_{1}^{\kappa} \tau_{i}\left(\tilde{\kappa} \bar{x}_{j}, \bar{x}_{j}, x_{-i, j}\right) d \tilde{\kappa} \\
& \geq \exp \{(\kappa-1-\ln \kappa) \underline{\rho}\}
\end{aligned}
$$

But $\kappa-1-\ln \kappa>0$. Hence, for $\underline{\rho}$ sufficiently large,

$$
p_{i}\left(\kappa \bar{x}_{j}, \bar{x}_{j}, x_{-i, j}\right)>\frac{2}{\kappa} p_{i}\left(\bar{x}_{j}, \bar{x}_{j}, x_{-i, j}\right),
$$

which contradicts (103). Hence, the assertion holds.

Lemma A.3. In any standard contest, $p_{i}\left(x_{i}, 0, x_{-i, j}\right) \leq 2 p_{i}\left(x_{i}, x_{i}, x_{-i, j}\right)$ holds for any $x_{i} \geq 0$ and any $x_{-i, j} \geq 0$.

Proof. Clearly, from anonymity,

$$
\begin{aligned}
p_{i}\left(x_{i}, x_{i}, x_{-i, j}\right) & =1-p_{j}\left(x_{i}, x_{i}, x_{-i, j}\right)-\sum_{k \neq i, j} p_{k}\left(x_{k}, x_{j}, x_{-j, k}\right) \\
& =1-p_{i}\left(x_{i}, x_{i}, x_{-i, j}\right)-\sum_{k \neq i, j} p_{k}\left(x_{k}, x_{j}, x_{-j, k}\right) .
\end{aligned}
$$


Hence, by monotonicity, and because the contest is standard,

$$
\begin{aligned}
2 p_{i}\left(x_{i}, x_{i}, x_{-i, j}\right) & =1-\sum_{k \neq i, j} p_{k}\left(x_{k}, x_{j}, x_{-j, k}\right) \\
& \geq 1-\sum_{k \neq i, j} p_{k}\left(x_{k}, 0, x_{-j, k}\right) \\
& =1-p_{j}\left(0, x_{i}, x_{-i, j}\right)-\sum_{k \neq i, j} p_{k}\left(x_{k}, 0, x_{-j, k}\right) \\
& =p_{i}\left(x_{i}, 0, x_{-i, j}\right),
\end{aligned}
$$

which proves the assertion. 


\section{References}

Alcade, J., Dahm, M. (2010), Rent seeking and rent dissipation: A neutrality result, Journal of Public Economics 94, 1-7.

Baik, K.H. (1998), Difference-form contest success functions and effort levels in contests, European Journal of Political Economy 14, 685-701.

Baye, M.R., Hoppe, H. (2003), The strategic strategic equivalence of rentseeking, innovation, and patent-race games, Games and Economic Behavior $44,217-226$.

Baye, M.R., Kovenock, D., de Vries, C.G. (1993), Rigging the lobbying process: An application of the all-pay auction, American Economic Review 83, 289-294.

Baye, M.R., Kovenock, D., de Vries, C.G. (1994), The solution to the Tullock rent-seeking game when $R>2$ : Mixed-strategy equilibria and mean dissipation rates, Public Choice 81, 363-380.

Baye, M.R., Kovenock, D., de Vries, C.G. (1996), The all-pay auction with complete information, Economic Theory 8, 291-305.

Broecker, T. (1990), Credit-worthiness tests and interbank competition, Econometrica 58, 429-452.

Che, Y.-K., Gale, I. (1998), Caps on political lobbying, American Economic Review 88, 643-651. 
Che, Y.-K., Gale, I. (2000), Difference-form contests and the robustness of all-pay auctions, Games and Economic Behavior 30, 22-43.

Cornes, R., Hartley, R. (2005), Asymmetric contests with general technologies, Economic Theory 26, 923-946.

Dasgupta, P., Maskin, E. (1986), The existence of equilibrium in discontinuous games, I: Theory, Review of Economic Studies 53, 1-26.

Dasgupta, P., Stiglitz, E. (1980), Uncertainty, industrial structure, and the speed of R\&D, Bell Journal of Economics 11, 1-28.

Dennert, J. (1993), Price competition between market makers, Review of Economic Studies 60, 735-751.

Dixit, A. (1987), Strategic behavior in contests, American Economic Review $77,891-898$.

Ellingsen, T. (1991), Strategic buyers and the social cost of monopoly, American Economic Review 81, 648-657.

Ewerhart, C. (2014), Mixed equilibria in Tullock contests, manuscript, University of Zurich, under review.

Fang, H. (2002), Lottery versus all-pay auction models of lobbying, Public Choice 112, 351-371.

González-Díaz, J. (2010), First-prize winner-takes-all contests, Optimization, forthcoming. 
Hillman, A.L., Riley, J.G. (1989), Politically contestable rents and transfers, Economics and Politics 1, 17-39.

Hillman, A.L., Samet, D. (1987), Dissipation of contestable rents by small numbers of contenders, Public Choice 54, 63-82.

Hirshleifer, J. (1989), Conflict and rent-seeking success functions: Ratio vs. difference models of relative success, Public Choice 63, 101-112.

Konrad, K.A. (2007), Strategy in contests - an introduction, WZB, Berlin.

Konrad, K.A., Kovenock, D. (2009), Multi-battle contests, Games and Economic Behavior 66, 256-274.

Loury, G.C. (1979), Market structure and innovation, Quarterly Journal of Economic 93, 395-410.

Moldovanu, B., Sela, A., Shi, X. (2007), Contests for status, Journal of Political Economy 115, 338-363.

Narasimhan, C. (1988), Competitive promotional strategies, Journal of Business $61,427-449$.

Pérez-Castrillo, J.D., Verdier, T. (1992), A general analysis of rent-seeking games, Public Choice 73, 335-350.

Siegel, R. (2009), All-pay contests, Econometrica 77, 71-92.

Siegel, R. (2010), Asymmetric contests with conditional investments, American Economic Review 100, 2230-2260. 
Skaperdas, S. (1996), Contest success functions, Economic Theory 7, 283-290.

Szymanski, S. (2003), The economic design of sporting contests, Journal of Economic Literature 41, 1137-1187.

Treich, N. (2010), Risk-aversion and prudence in rent-seeking games, Public Choice 145, 339-349.

Tullock, G. (1980), Efficient rent-seeking, in Buchanan, J., Tollison, R., Tullock, G. (eds.), Toward a theory of the rent-seeking society, Texas A\&M University Press, College Station, pp. 97-112.

Varian, H.R. (1980), A model of sales, American Economic Review 70, 651659.

Wang, Z. (2010), The optimal accuracy level in asymmetric contests, B.E. Journal of Theoretical Economics 10(1), Article 13.

Yang, C.-L. (1994), A simple extension of the Dasgupta-Maskin existence theorem for discontinuous games with an application to the theory of rentseeking, Economics Letters 45, 181-183. 